\title{
Management instrumentarium of innovation development of medium-sized industrial enterprises
}

\author{
L. Ismagilova ${ }^{1, *}, L$. Sitnikova ${ }^{1}$, and $N$. Klimova $^{2}$ \\ ${ }^{1}$ Ufa State Aviation Technical University, USATU, Ufa, Russian Federation \\ ${ }^{2}$ Institute of social and economic researches of Ufa scientific centre of Russian Academy of Science, ISER USC of RAS, Ufa, \\ Russian Federation
}

\begin{abstract}
The article is devoted to the development management of industrial enterprises related to medium-sized businesses and working in the field of product innovation. In the article there were investigated the methods and management features, the factors, constraining innovation processes in industrial companies. The theoretical background of solving innovation development and maintaining economic stability contradictions were identified. The results of the comparative assessment of small and medium-sized enterprises were unveiled. In paper there were revealed the features and benefits of the transition to the innovative products. A method of positioning matrix and the typology of enterprises in terms of economic sustainability and innovation were proposed. There was worked out a graph-analytical management tool for middle-sized industrial enterprises on the basis of a balance of innovative activity and economic sustainability. For a given industrial enterprise there was formed an effectively balanced portfolio of products at different stages of the life cycle.
\end{abstract}

\section{Introduction}

Functioning and development of industrial enterprises in the innovation-oriented environment of the real sector of the production involves in the processing chain businesses of different sizes (large, medium and small forms). The main purpose of the formation of such chains is to maximize the added value at the each stage of the technology cycle, primarily due to the innovative development. However, practice of building such chains has not received proper promotion in the Russian practice, as the evaluation of the role and importance of small and medium enterprises in the Russian economy is ambiguous. With their considerable share in the total number of enterprises, the contribution to GDP remains at $20 \%$. In most statistical studies of small and medium enterprises they fall into one analytical group that does not seem quite correct due to fundamental differences. As noted in [1], adopted criteria for classifying enterprises to groups of small, medium and large are enough conventional and have been introduced in accordance with the established practice of statistical reporting. The features of the medium-sized enterprises in a number of cases are similar to business entities of both large and small size. The analysis of official statistics $[2,3]$ shows that the majority of medium-sized enterprises (up to $42 \%$ of the total) is concentrated in the sectors with high value added. This is the first of all manufacturing industry. At the same time, the average number of medium-sized businesses is closer to the corresponding characteristic of large enterprises.
The increased attention is being paid to the development of small businesses, overshadowed the importance of medium-sized industrial enterprises in modern economy of Russia. The interest in the businesses of this size group may be explained by a number of reasons:

- that is, as a rule, fast-growing companies that could potentially provide an innovative breakthrough in the economy; in [4] it is noted that they are able to generate more than $20 \%$ of innovative ideas and become a launching pad for the introduction of new technical and technological developments;

- medium-sized industrial enterprises comparing with the enterprises of small forms have higher capital intensity associated with longer production cycle in the production of added value. Of course, the range and volume of output of midsize enterprises group is significantly lower than the corresponding figures of large enterprises;

- medium-sized enterprises provide a high rate of profitability due to innovation activity. At the same time small businesses achieve high yield in the segments with high margins without adding value (retail, real estate, etc.);

- another important advantages of medium-sized enterprises are the possibilities of their transformation (division or integration), the purpose of which is to choose more effective forms of organizing production. In addition, studies show that large enterprises are more willing to cooperate with medium-sized enterprises. Thus, medium-sized enterprises, on the one hand, are

Corresponding author: ismagilova_ugatu@mail.ru 
able to act as a donor for small businesses, and on the other - are the points of growth and innovative development for large businesses;

- the growth potential of medium-sized enterprises effectiveness is much higher than in small ones. It is comparable to large companies, and even higher in some cases. The share of medium-sized enterprises in providing employment is smaller than their share in the total turnover. This shows quite effective level of using the workforce and a high capacity for innovation development. In some cases, the values of these parameters exceed the industry average levels and general economic level of labor and innovation efficiency.

An important condition for the providing of competitiveness and sustainability of medium-sized businesses is the ability to respond flexibly to the market situation development. These businesses do not have considerable recourses reserves and stability of large enterprises. Their mobility is lower than mobility of small businesses. Therefore, a specific mechanism to ensure stability of this group of companies have to be formed. In modern conditions the basis of this mechanism is implementation of innovation.

\section{Relevance}

The solution of innovative-active medium-sized enterprises control problem involves the integration of theoretical and methodological approaches in several areas of research. Among them are the competitiveness and innovation management, strategic and economic management, and others.

The analysis showed that the vast majority in developing concepts and tools of strategic management research, including the provision of long-term competitiveness, for example [5-9], is aimed at large enterprises. Much attention is paid to the management of small business development because of its specificity and "the declared" role as a "driver" of economic growth [10], of economic activity of small businesses [11]. The features of medium industrial enterprises management, the choice of effective methods of management, according to the possibilities of innovation growth is not being researched and developed enough nowadays.

Thus, the solution of the problem of insurance medium-sized enterprises competitiveness in the innovation economy requires as target the following objectives:

- systematization of the characteristic features of the industrial medium-sized enterprises, identifying factors of external influence on the efficiency of operations;

- developing the effective management tools for medium-sized enterprises innovation activity as the basis for achieving competitive advantages in integrated criterion of economic stability.

Studies have shown that the implementation of innovations in different periods of medium-sized companies development influence on its resulting characteristics in different ways $[12,13]$. In the perspective, innovations contribute to the stability achievement, but the initial moment of their implementation, as a rule, is associated with the violation of financial and economic stability. In this context, the development of methods and management tools for medium-sized enterprises, which would provide coordination of innovative development goals and maintenance an effective production and economic performance is certainly relevant from both the scientific and practical points of view.

\section{3 "Innovative activity" vs "Economic stability"}

As noted above innovation changes in technology and organization of production at the initial stage of their implementation are acting in conflict with the main economic interest in any business entity - the preservation of a stable position. One of the main causes of this contradictory situation is high risk and high cost of innovations. As the result there is forming an objective need to find a compromise between the need to improve the innovation activity and the ability to maintain economic stability. For large-scale industrial enterprises, this contradiction is eliminated by attracting sufficient resources and better use of existing capacity. But for medium-sized enterprises, this contradiction can be critical in certain circumstances.

In economic researches there are presented different interpretations of the concepts of "innovation activity" and "economic sustainability" [14-16]. In the context of this study the innovation activity refers to the company's ability to implement innovations faster than the competitors and strengthen the long-term market position. Innovative activity must not only be provided with financial resources. At the same time it must be supported by appropriate financial activity, which is characterized by the speed of funds involving innovative solutions for challenges in a competitive time. This is appropriate to maintain a positive balance of cash flow, which is an indicator of financial stability [17]. To resolve this contradiction of economic and management approach there is proposed the matrix of ranking companies based on multivariate classification and infographical model.

The method allows justify management decisions based on changes in the competitive situation of the enterprise status and levels of economic stability. The method is based on multivariate classification process presented in the form of related matrices. Based on the identified characteristics of medium-sized enterprise management it is expedient to classify companies into four competitive statuses:

- Type "C1 - advanced" - is an enterprise with high competitiveness, with strong innovative capacity, high ability to realize the full innovation cycle in a competitive time and financial capacity. The complex of these characteristics determines the high level of competitiveness, which is ensured by the high innovation activity. According to statistics, this type is common to large and medium-sized enterprises - about 8-12\%; and less than $1 \%$ of small businesses; 
- Type "C2 - conservative" - the average level of competitiveness with innovative potential, which is insufficient to provide innovative products the market needs. The source of holding competitive position is a temporary position of monopoly, which allows obtain sufficient financial resources for the development of non-innovative movement. According to the estimates this type includes about $20-25 \%$ of large and mediumsized enterprises and about $5 \%$ of small businesses in Russia;

- Type "C3 - risking" - the average level of competitive enterprises with a significant potential for innovation, and limited financial resources. With these characteristics, they are either involved in innovative projects with a high level of profitability and risk, or middle income projects carried out with a moderate level of risk. Upon successful implementation of projects, enterprises receive financial resources for the next innovation project. In the case of failure the financial stability of the enterprise is disrupted. This type includes about $45 \%$ of large and medium, as well as more than $50 \%$ of small businesses;

- Type "C4 - surviving" - enterprises with low competitiveness, which are not able to satisfy market demand with innovative products in a competitive time and do not have the financial capacity to deal. These include $10-20 \%$ of large enterprises, $45 \%$ of medium and $50 \%$ of small businesses.

The specification of "economic stability" definition in respect to innovative businesses let us make a conclusion that economic stability performs as the condition of their competitiveness and linked with such key features as innovative and financial activity.

The proposed method of matrix positioning allows, except for the classification of companies on the content and type of competitive status, hold intraspecific classification of enterprises in terms of economic stability. The method presented in the form of a two-step transition from the matrices. This transition defines content management solutions and justifies the strategy of innovative development of the industrial enterprise. Formation of development strategy is based on the sequential selection of the enterprise features in a particular economic and production situation. There were highlighted four levels of positioning companies based on the criterion of economic stability, taking into account the characteristics mentioned above, as well as the possible risks: AES, ES, CES, EI, as shown in Fig. 1. Levels determined by activity performance indicators and active involvement of financial resources.

The combination of high values of these parameters (level AES) provides the coordination of possible contradictions and can achieve a balanced innovation behavior of the average enterprise. Companies with this level of sustainability are highly innovative enterprises, for their effective functioning it is important to maintain as financial stability, and activity in the field of innovation.

Level ES reflects the situation when innovative activity of the enterprise is accompanied by a low level of financial stability or low level of financial activity. In both cases, the economic stability cannot be guaranteed to be secured in the long term.

Level CES reflects the unfavorable situation, characterized by a combination of a high level of innovation activity and low levels of financial stability and activity. It is also considered as unfavorable a situation when insufficient level of financial stability combines with low innovative level. Any manifestation of innovation activity will lead to imbalances and bankruptcy.

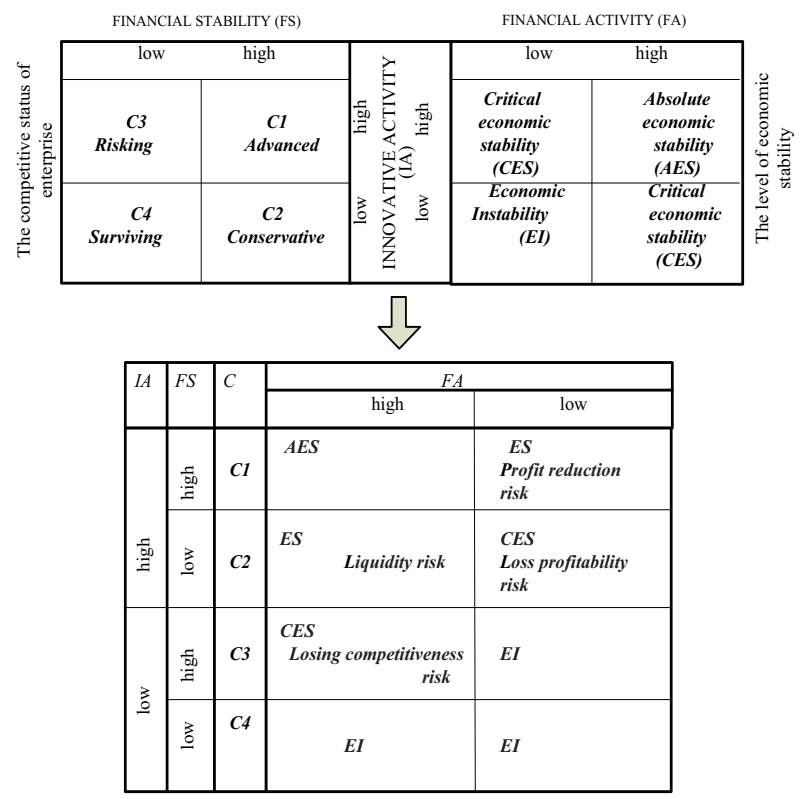

Fig. 1. Enterprise positioning in terms of economic stability.

Various combinations of low levels of indicators (level EI) define crises situations in which business strategy performs irrational innovative behavior, which leads to disparities of resources and strategic perspectives.

The analysis shows that innovative activity and economic stability although conflict, nevertheless working on the long-term competitiveness of medium enterprises [18].

Thus, the specificity and the key problem of organization and management at medium innovative enterprises is the harmonization of administrative decisions in planning and release of innovative products. It is possible to ensure the maintenance of the conflicting interests balance, using the matrix ranking method.

\section{Info-graphical tool for innovation- active industrial enterprises management}

The elimination of innovative development contradictions and the economic stability of the enterprise is carried out in the development of production plans. The solution lies in the optimization of the product portfolio on the criterion of economic balance of the results obtained from the products at different stages of the life cycle [19-21]. 
The idea of coordinated management implemented in practice in developed model of infographic (Fig. 2.) and algorithms of analysis of relative indicators: price and output plan, fixed and variable costs, profit (loss).

Info-graphical model as a tool to validate management decisions makes it possible to:

- determine the effective output plan at fixed costs and target value of the relative profits;

- calculate the value of a possible profit at fixed release schedule, costs and prices;

- set the price based on the output plan, costs and targeted level of profitability;

- estimate the required amount of fixed costs for a given output plan, set the variable costs, product prices and the relative profitability;

- identify the effective ratio of fixed and variable costs for specific values of prices, variable costs and profitability;

- set the possible correlation of economic indicators of info-graphical model according to target level of profitability.

Info-graphical model as a tool of management decisions validation, allows us to implement contingency management synchronous in several ways due to the wide field of information. In addition, this model ensures the validity of the decision-making under conditions of conflicting goals and visual coverage of managerial situations, determined by a combination of economic parameters.

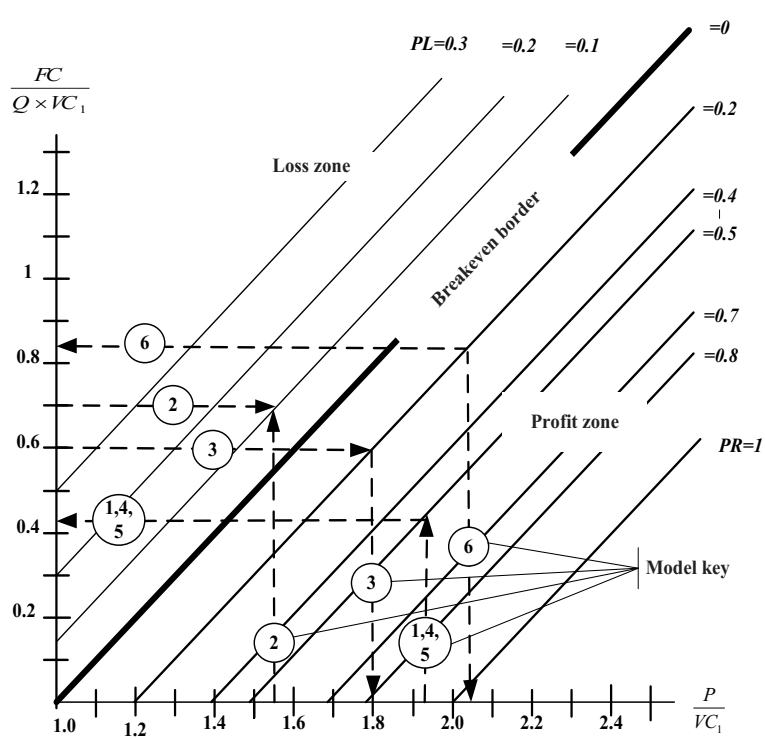

Fig. 2. Info- graphic model of economic indicators planning for the criterion of profitability ( FC - fixed costs, $\mathrm{Q}$ - output, $\mathrm{VC}_{1}$ - variable costs per unit, P - price, RP (RL) - Relative profit / loss; 1, 2, 3, 4, 5, 6 - types of management decisions).

\section{Practical application}

The model above was tested on the one of medium-sized enterprises of "Machinery and equipment" economic activity of the Bashkortostan Republic.

During 2014, the company was unable to provide a profit on new products. For a number of not-innovative competitive products which are at the saturation point, the economic indicators have reached an acceptable level, but not enough to ensure the flow of financial resources allocated for the maintenance of innovative products. The established balance of economic indicators corresponds with the situation "C2-ES" by the method of positioning the matrix (Fig. 1).

One of such products is the directly fuel kiln. According to the info-graphic model (Fig. 3), with the initial values of economic parameters (the price of the product is 2447.37 money units (m.u.), variable costs are 1786.4 m.u., fixed costs are 1031110 m.u., volume of output is 1480 units) the level of relative loss of this product is:

$$
\begin{aligned}
R L^{2014}=1-\frac{P}{V C_{1}} & \times \frac{1}{\left(1+\frac{F C}{Q V C_{1}}\right)}= \\
& =1-1.37 \times \frac{1}{1+0.39}=0.014
\end{aligned}
$$

The development of strategic decisions about the enterprise transfer into a more favorable situation realize by means of the proposed instruments. As the target criteria there was set a level of relative profitability of the product is not lower than 0.11 . Target profitability value (at the same cost) is achievable by varying the price and release plan. Using the info-graphic model it was justified the sequence of administrative decisions formation. With an increase in prices to $2536,69 \mathrm{~m}$.u. on the info-graphical model (Fig. 3) there was determined the appropriate balance of costs:

$$
\frac{P}{V C_{1}}=1.42 .
$$

During solving the problem in the graphicalanalytical model (Fig. 3) there was defined the ratio:

$$
\frac{F C}{Q \times V C_{1}}=0.28
$$

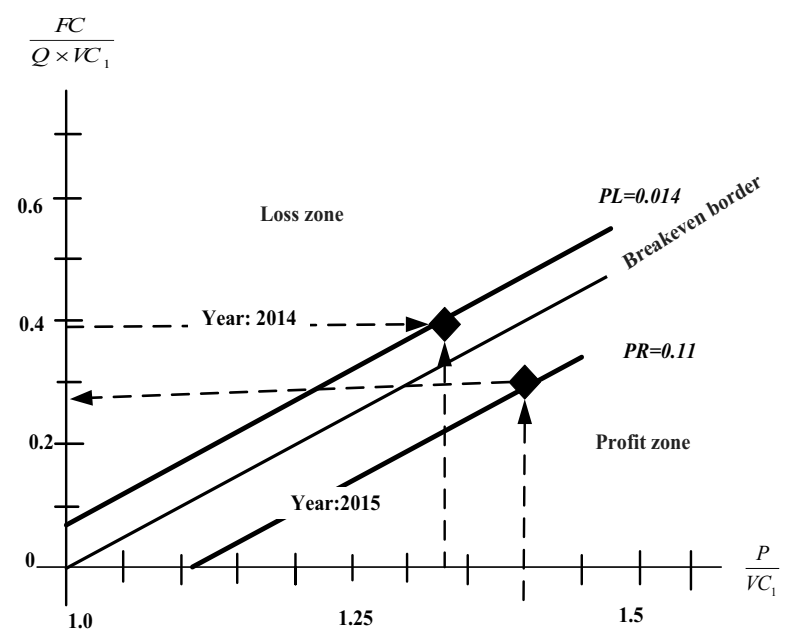

Fig. 3. Modeling of targeted economic parameters. 
This ratio corresponds to the release of 2060 units, and profit on the position "directly fuel kiln" amounted to 518220 m.u.

Similar calculations for all product items allowed to determine portfolio structure of products with different positioning on the life cycle stages (Table. 1).

Table 1. Product portfolio.

\begin{tabular}{|c|c|c|c|}
\hline $\begin{array}{l}\text { Position of } \\
\text { portfolio }\end{array}$ & Year & $\begin{array}{l}\text { Profit on } \\
\text { realization }\end{array}$ & $\begin{array}{l}\text { Changes } \\
\text { of profit }\end{array}$ \\
\hline \multirow{2}{*}{$\begin{array}{l}\text { Directly fuel kiln } \\
\text { (on gas and liquid } \\
\text { fuels) }\end{array}$} & 2014 & - & \multirow{2}{*}{+518220} \\
\hline & 2015 & +518220 & \\
\hline \multirow{2}{*}{ Dosing system } & 2014 & 346406 & \multirow{2}{*}{-262533} \\
\hline & 2015 & 83873 & \\
\hline \multirow{2}{*}{$\begin{array}{l}\text { System of gaz } \\
\text { distribution in } \\
\text { gazlift well }\end{array}$} & 2014 & 47093 & \multirow{2}{*}{+79700} \\
\hline & 2015 & 126793 & \\
\hline \multirow{2}{*}{$\begin{array}{l}\text { Electro-fulfilment } \\
\text { regulating device }\end{array}$} & 2014 & 68086 & \multirow{2}{*}{+259933} \\
\hline & 2015 & 328019 & \\
\hline \multirow{2}{*}{ Oil metering unit } & 2014 & 58908 & \multirow{2}{*}{+30164} \\
\hline & 2015 & 89072 & \\
\hline $\begin{array}{l}\text { Liquid fuel } \\
\text { preparation block }\end{array}$ & 2012 & 31794 & +31794 \\
\hline Total & & & +657278 \\
\hline
\end{tabular}

The resulting balanced portfolio provides the smoothing of contradictions of innovative behavior and economic sustainability.

\section{Conclusion}

As a result of the comparative evaluation there were revealed the features and benefits of medium-sized business entities in the manufacturing of innovative products. There was proposed the classification of medium-sized enterprises according to the criterion of competitiveness, which differs from the existing classification by complex measurement the of innovation activity parameters and financial stability. The problem of resolving economic and managerial contradictions arising in industrial enterprises of the middle class was examinated. there was set and solved the problem of elimination of contradictions between the need of innovation production and financial constraints.

In the paper there was proposed a method of matrix positioning and info-graphic tool to validate management decisions to ensure the competitiveness of innovative enterprises. For a balanced portfolio of products is formed through coordinated control at different stages of the life cycle and thus providing financial support for innovation. The approbation of the developed instruments proved its high importance for the effective management of medium-sized industrial enterprises.

The study was sponsored by the RFH and the Academy of Sciences of Bashkortostan, the project number 15-12-02020.

\section{References}

1. V.V. Kotov, The Economic Journal, 23, 90-101 (2011)

2. Small and medium business in Russia. 2014: statistical publication (Rosstat, Moscow, 2014)

3. Russia by the Numbers (Rosstat, Moscow, 2015)

4. V.V. Andreev, M.P. Galimova, Intelligence, innovation, investment, 1, 21-25 (2013)

5. G.B. Kleiner, V.L. Tambovtsev, R.M. Katchalov, Enterprise in an unstable economic environment: risks, strategy, security (Economics, Moscow, 1997)

6. D. Aaker, Strategic market management (Peter, St. Petersburg, 2007)

7. I. Ansoff, Strategic Management: classic edition (Piter, St. Petersburg, 2009)

8. R.M. Grant, Modern strategic analysis (Peter, St. Petersburg, 2008)

9. O.N. Melnikov, V.N. Shuvalov, Russian Entrepreneurship, 9(69), 100-104 (2005)

10. F.A. Babayev, Problems of Forecasting, 4, 136-142 (2005)

11. I.A. Baev, M.V. Podshivalova, The economy of the region, 1, 189-198 (2013)

12. V.V. Andreev, M.P. Galimova, L.V. Sitnikova, Journal of Economic Integration, 7, 16-22 (2013)

13. L.A. Ismagilova, T.A. Gileva, L.V. Sitnikova, Theoretical and practical aspects of management, $\mathbf{9}$, 62-71 (2015)

14. A.D. Kanchaveli, A.A. Kolobov, I.N. Omelchenko, Strategic management of organizational-economic stability of the company (MSTU. Bauman, Moscow, 2001)

15. L.T. Gilyarovskaya, A.A. Vehoreva, Analysis and assessment of financial stability of business (Piter, St. Petersburg, 2012)

16. S.N. Anokhin, Technique of modeling of industrial enterprises economic stability in modern conditions (Saratov State Technical University, Saratov, 2006)

17. L.A. Ismagilova, M.P. Galimova, Herald USAES. Science, education, economy. Series: Economy, 2, 78-81 (2012).

18. V.A. Dines, V.M. Larin, R.Y. Loskutov, N.S. Yashin, Competitiveness and economic stability of the enterprise (Publishing Center SSSEU, Saratov, 1999)

19. O. Bastrikova, L. Sitnikova, Management in Russia and abroad journal, 4, 77-87 (2009)

20. L.A. Ismagilova, E.V. Orlova, Proc. of the $8 h$ Int. Workshop on Computer Science and Information Technologies CSIT, 453-457 (2006)

21. L.A. Ismagilova, T.A. Gileva, M.P. Galimova, Innovation Activity, 1(32), 63-73 (2015) 